\title{
The positive effects of a peer-led intervention system for individuals with a risk of metabolic syndrome
}

\author{
Aree Sanee \\ Ratana Somrongthong \\ Samlee Plianbangchang \\ College of Public Health Sciences, \\ Chulalongkorn University, Bangkok, \\ Thailand
}

\author{
This article was published in the following Dove Press journal: \\ Journal of Multidisciplinary Healthcare \\ II August 2017 \\ Number of times this article has been viewed
}

Correspondence: Aree Sanee College of Public Health Sciences, Chulalongkorn University, Institute Building 3, 10 floor, Soi Chulalongkorn 62, Phyathai Rd, Pathumwan, Bangkok 10330, Thailand

Tel +66883068036

Email aoodya@yahoo.com
Background: Metabolic syndrome (MetS) is a major health risk in Thailand. Although it is reported that females have a higher rate of MetS than males, very few peer-led intervention studies have been conducted on specific groups, such as seamstresses, at risk of MetS. This study aimed to evaluate the effect of a peer-led intervention program on reducing MetS risk factors in individuals working in Thai Uniform Sewing Military Factories.

Methods: A quasiexperimental program was introduced using a pre- and posttest design that was applied to female sewing factory workers selected for this research. All participants had at least one of the key MetS symptoms. The experimental group ( $\mathrm{N}=50$ participants) received 12 weekly peer-led individual support discussion sessions that included both dietary and physical activity (PA) advice and the control group ( $\mathrm{N}=50$ participants) followed their usual daily routines. The Student's $t$-test and the Pearson's chi-squared test were used to compare the differences of baseline data and analysis of variance was used for analysis of the data after intervention.

Results: The results showed that after 3 months of participation, when compared to the control group, the experimental group had significantly improved systolic blood pressure $(\mathrm{BP})(P=0.04)$, diastolic BP $(P<0.001)$, PA $(P=0.05)$, knowledge scores of MetS, perception of MetS and risk factors $(P<0.001)$, and stress assessment $(P=0.002)$. Waist circumference, body mass index, and Food Frequency Questionnaire score were not significantly different but still improved.

Conclusion: Findings from this study suggest that a peer-led support program can be introduced as an effective means of improving the behaviors of mostly sedentary factory workers at risk of MetS caused by working habits that are detrimental to health.

Keywords: peer-led intervention, individuals, metabolic syndrome

\section{Introduction}

The number of overweight and obese people is continuously increasing both in the developed and in developing countries. Excess weight and obesity coupled with advancing age increase the threat of a cluster of abnormalities referred to as metabolic syndrome (MetS). Risk factors including waistline obesity, elevated triglyceride levels, reduced high-density lipoprotein (HDL) cholesterol levels, raised blood pressure (BP), and raised fasting plasma glucose are well documented. ${ }^{1}$ Over a 23 -year period, the National Health Examination Survey (NHES), Thailand, was conducted five times - in 1991, 1996, 2004, 2009, and 2014 - to assess the health and nutritional status of Thai people. From the first to the fourth survey, obesity prevalence in Thailand had increased $>2.5$ times. $^{2,3}$ In the 1991 and 1996 surveys, the obesity prevalence for females was approximately two times higher than that of their male counterparts, whereas in 2004, 2009 , and 2014 surveys, the ratio of obese females to males had reduced to $1.5,1.4$, 
and 1.3, respectively. ${ }^{4}$ In addition, data from the fourth NHES, Thailand, on public health examination (2008-2009) reported that 20,450 of its working age population and elderly people have MetS including above standard averages in body mass index (BMI), waist circumference (WC), diabetes mellitus, and cholesterol disorders. The last Thailand NHES (2014) reported that the prevalence of MetS in the Thai population aged 15 years and older was $21.7 \%$ (24.5\% in female and $18.9 \%$ in male). ${ }^{5}$ Results of the 2014 survey showed that the prevalence of obesity in males reflects the trend from previous years and rose to $33 \%$, while the prevalence in females increased only slightly to $43 \%$. Thailand has now become one of the countries with the highest prevalence of obesity in Asia (second only to Malaysia). ${ }^{6}$ This alarming statistic that is linked to increasing global obesity can be attributed to changes in economic development, modernization, and urbanization. $^{7}$

In previous research, peer-led intervention programs have been, and continue to be, used effectively in other countries to address diverse problems. This intervention program has been previously assessed and used with successful results in Asia $^{8-13}$ but not in Thailand.

In Thailand, there have been many strategies and attempts at intervention to change the health behaviors of general or specific groups of the population affected by MetS. The Ministry of Public Health (MOPH) is the principal agency responsible for promoting, supporting, controlling, and coordinating all health service activities for the well-being of the Thai people. ${ }^{14}$ From 1996 to 2005, the MOPH endorsed a foodbased dietary guideline and nutrition program and launched a public healthy meal planning campaign. Furthermore, the US Food and Drug Administration (FDA) implemented the guideline for daily amounts of saturated fatty acids, sugar, and sodium on a voluntary basis. ${ }^{15}$ In addition, the Thai Health organization deploys four channels in promoting health: namely, health promotion through issues (alcohol, tobacco, unhealthy foods, etc), organizations (educational institutions, workplaces, etc.), communities or areas, and target groups (children, vulnerable populations, elderly, etc.). Also, the Thai Health Organization supports epidemiological and policy research related to obesity in Thailand, promotes public health awareness, and advocates national and local policy on healthy diet and physical activity (PA). ${ }^{4}$

In Thailand, most studies on garment factory workers focused on a cross-sectional analytical study and most researchers were interested in musculoskeletal disorders or occupational hazards, ${ }^{16-19}$ but no experimental peer-led intervention studies have been conducted on the risk of seamstresses developing MetS as a consequence of their occupation. The research presented in this study can, however, be applied to all prolonged seating occupations, but focused on seamstresses, as the research team was granted access to two identical but separately located governmentregulated garment factories, making the research scope and environment easier to assess and monitor due to its structured environment. The results of this study can effectively form the basis of similar future studies on the health effects of other sedentary occupations. The authors recognized the crisis situation faced by an increasing number of female workers in the factory presenting with MetS symptoms. The aims of this study were to evaluate the effect of a peer-led intervention program on reducing MetS symptoms and to improve the knowledge of MetS, its risk factors, and the importance of preventative measures such as increased PA, improved diet, and reduced stress, as well as to reduce some clinical parameters, such as WC, BMI, systolic BP, and diastolic BP.

\section{Methods}

\section{Experimental design}

Quasi-experimental research designs, where assessments were performed before and after the program, were applied to this study and employed from September 15 to December 16, 2015. This study took place in two separate locations, namely, the Uniform Sewing Factories of the Royal Thai Army in Nonthaburi province for the intervention group and the Uniform Sewing Factories of the Royal Thai Navy located in Bangkok for the control group. The decision to separate the control group from the experimental group was due to time constraints that restricted the ability to better monitor and avoid information sharing of data findings if both groups were within the same, close-knit, working environment. By having the staff working in geographically separate yet near identical working conditions, the research team ensured the ability to monitor results as outlined in the planned experiment within the restricted timescale.

\section{Subjects}

A 12-week study was conducted with 100 individuals between the ages of 35 and 59 years to assess the feasibility of the methods. In order to be eligible, volunteer participants had to present with at least one of the following MetS symptoms: 1) waistline obesity ( $\mathrm{WC} \geq 80 \mathrm{~cm}), 2$ ) raised triglyceride levels ( $\geq 150 \mathrm{mg} / \mathrm{dL}), 3)$ reduced HDL cholesterol $(<50 \mathrm{mg} / \mathrm{dL})$, 4) raised BP (systolic $\geq 130 \mathrm{mmHg}$ or diastolic $\geq 85 \mathrm{mmHg}$ ) or treatment of previously diagnosed hypertension, and 5) raised fasting plasma glucose $(\geq 110 \mathrm{mg} / \mathrm{dL})$ or diagnosed 
type 2 diabetes. In addition, participants had to be willing and able to communicate by mobile phone. Volunteers were ineligible to participate if they had any of the following: diseases including cardiovascular diseases, chronic liver or kidney disease, advanced cancer, and/or requiring specific diet and exercise recommendations. They were also ineligible if they were unable to participate in the study for its entire duration due to pregnancy, change in workplace, or temporary worker status. A total of 50 eligible participants for each group were randomly selected from among the high number of applicants who expressed an interest in participating in this study. Afterward, 100 eligible participants gave their permission by signing an informed consent form approved by the Ethical Committee for Research Involving Human Subjects, Health Science Group from Chulalongkorn University (COA No. 142/2016) before commencement of the study.

\section{Sample size calculation}

This study used a $G$ power program to calculate the sample size necessary to obtain estimates of a desired precision. Based on a previous study, ${ }^{20}$ the effective size of 0.24 , the alpha level of 0.05 , and a power of 0.80 were used. A total of 100 females who fit the criteria were selected.

\section{Intervention}

The study program consisted of the following two parts: the first part involved peer leader training lasting 5 weeks and the second part involved a preplanned program implemented by peer leaders lasting 3 months.

\section{Peer leader training program}

The 55 participants in the intervention group were divided into five groups of 10 members plus one peer leader. A peer leader to lead each group had to be selected within the group. The selection criteria prior to the commencement of training included: 1) age range from 35 to 59 years; 2) at risk of MetS for more than half a year; 3 ) education level to at least bachelor's degree to facilitate better dissemination of the program's goals; 4) ability to communicate verbally; 5) willingness to be involved in this study as a peer leader; and 6) confidence and sensitivity to self-management behavior. Leaders for each of the five intervention groups were selected from among the group following peer nominations and section supervisor recommendations from the Uniform Sewing Factory of the Quartermaster Department of Royal Thai Army where the study took place. Each peer leader was responsible for ten participants in her group. Eight peer leaders were originally nominated, so the researcher also interviewed candidates recommended by the supervisor in order to narrow down to the final five selected peer leaders.

The training course for peer leaders involved brainstorming and discussion and was developed following recommendations by the research team together with the peer leaders. The research team comprised a nurse manager in chronic diseases, a dietitian, a sport scientist, and a Tai Chi instructor. The total training course was 13 hours long and comprised five educational sessions (basic MetS knowledge) and four workshop sessions (body weight and WC measurement, healthy diet/reading food labels, PA recommendations, and stress management).

\section{Intervention by peer leaders}

As a part of the 3-month peer-led intervention, each participant was provided with a handbook about MetS, PA, healthy diet, and stress management. The intervention section consisted of the following two parts: whole-group (all 50 participants) support sessions led by the five peer leaders and weekly small-group sessions (ten participants) led by each team's peer leader.

The weekly small-group support sessions of 30 minutes duration were organized by each group's peer leader. Each support session was designed to strengthen peer support and facilitated group discussion and learning by sharing experiences and problem-solving strategies with each other. Participants were encouraged to meet their leaders individually or communicate by phone if they wished to discuss aspects of the program individually rather than in a group.

For the large group activity, peer leaders together with the research team conducted monthly meetings ( 2 hours long). Members of each team had activities for the group to complete at each meeting as follows: 1) setting their goal to lose weight and decide on how many kilograms per week, 2) combined the weight of members in each group, 3) finding the successful group who lost the most weight, so such team would get the 10 points from each meeting, 4) discussing and sharing experiences within groups and between groups, including tailored solutions for perceived barriers, and 5) on the 12 th week, evaluate the weight of each team. Log books were given to participants to monitor leisure time exercises and dietary habits and were shown to peer leaders at each group session. Furthermore, participants were required to record their weight on a weekly basis in the record book and were required to submit their record book to their peer leaders during the group meeting.

The aims of this section were to set personalized goals with participants, educate them on healthy eating habits 
and PA for weight management, address personal barriers to behavioral change, maintain motivation, and encourage them to use the additional program materials available. At each individual counseling session, participants were asked about their current body weight, diet, and PA in order to set goals to be achieved at their next meeting ( $~ 2$ or 3 weeks). Each time, one target goal was set with participants relating to their body weight and diet or PA

\section{Control group}

The information (handbook) that was given to the control group related to general information on the research objectives and the research schedule as a means of recruiting volunteers. The authors did not give any advice or offer further support as in that received by the intervention group.

\section{Data collection and measurements}

Data were collected from both the intervention and control groups at baseline and in the third month to assess mean changes. Measurements consisting of sociodemographic characteristics, systolic BP, diastolic BP, BMI, and WC were determined. Height and weight were measured according to World Health Organization (WHO) protocol. ${ }^{21,22}$ Height was measured to $\sim 0.1 \mathrm{~cm}$ using a tape fixed to a wall. A digital scale was used for measuring weight and calibrated before the examination. BMI was calculated as weight in kilograms divided by the square of height in meters. WC was measured using a nonstretch, spring weighted anthropometric tape with a tension meter attached in the horizontal plane. ${ }^{23}$ BP measurement was collected using an OMRON HEM-907XL automated BP monitor. ${ }^{24}$ All clinical measures were assessed by qualified nurses. Knowledge and perception questionnaires of MetS and risk factors were developed by the literature reviews, and then, three experts in the field of chronic diseases reviewed and commented on the questionnaire (Cronbach's alpha coefficients $=0.760$ and 0.845 , respectively). The Food Frequency Questionnaire (FFQ) from previous studies ${ }^{25-29}$ was modified for the purpose of this study (Cronbach's alpha coefficient $=0.760$ and 0.845 was used) and further validated by experienced subject specialists. PA was applied from the international physical activity questionnaires (IPAQ), ${ }^{30}$ and data were converted to metabolic equivalent task minutes per week (MET-minute/week). Stress assessment questionnaires were developed by Juckaphan et al, ${ }^{31}$ from the Department of Mental Health, MOPH, Thailand, by applying the pattern of the instruments for evaluating stress. ${ }^{32}$ All questionnaires had proven validity and reliability before commencement of this study.

\section{Data analysis}

A Student's $t$-test and a Pearson's chi-squared test were used to compare the differences of baseline data between the intervention group and the control group. In addition, repeated measure analysis of variance (ANOVA) was used to test the effect of the intervention program between the intervention group and the control group. Before data analysis, a sphericity test was used for the assumption of equal variances in ANOVA.

\section{Results}

The characteristics of participants are presented in Table 1. The total number of participants was 100 including 50 individuals in the intervention group and 50 individuals in the control group. Results revealed that sociodemographic characteristics pertaining to income and social support were similar in both groups $(P$-value $>0.05)$. After intervention, upon comparison of the two groups, there were statistically significant differences after 3 months between the intervention group and the control group. Also, the results showed significant differences of outcomes in the intervention group (Tables 2 and 3)

Table I Comparison of sociodemographic characteristics between the intervention group and the control group at baseline

\begin{tabular}{|c|c|c|c|}
\hline Characteristics & $\begin{array}{l}\text { Intervention } \\
(n=50) \\
n(\%)\end{array}$ & $\begin{array}{l}\text { Control } \\
(n=50) \\
n(\%)\end{array}$ & $P$-value \\
\hline \multicolumn{4}{|l|}{ Marital status } \\
\hline Married & $31(62)$ & $27(5 \mathrm{I} .1)$ & $0.77^{\mathrm{a}}$ \\
\hline Single & $9(18)$ & II (22.4) & \\
\hline Divorced/separated & $10(20)$ & II (22.4) & \\
\hline \multicolumn{4}{|l|}{ Educational attainment } \\
\hline Primary school & $14(28)$ & $9(18.4)$ & $0.22^{\mathrm{a}}$ \\
\hline Secondary school & $24(48)$ & $32(65.3)$ & \\
\hline $\begin{array}{l}\text { Vocational diploma/ } \\
\text { bachelor degree }\end{array}$ & $12(24)$ & $8(16.3)$ & \\
\hline \multicolumn{4}{|l|}{ Income } \\
\hline Enough and can be saved & $16(32)$ & $6(12.2)$ & $0.04^{\mathrm{a}}$ \\
\hline Enough but cannot be saved & $21(42)$ & $22(44.9)$ & \\
\hline Not enough & $13(26)$ & $21(42.9)$ & \\
\hline \multicolumn{4}{|c|}{ Chronic disease diagnosed by a doctor } \\
\hline Yes & $28(56)$ & $19(38.8)$ & $0.06^{\mathrm{a}}$ \\
\hline \multicolumn{4}{|c|}{ Taking medication related to their diseases } \\
\hline Yes & $28(56)$ & $19(38.80)$ & $0.07^{\mathrm{a}}$ \\
\hline \multicolumn{4}{|l|}{ Social support for PA } \\
\hline Having friends & $17(34)$ & $38(77.6)$ & $<0.00 I^{\mathrm{a}}$ \\
\hline Having family & $19(38)$ & $29(59.2)$ & $0.03^{\mathrm{a}}$ \\
\hline Age in years: mean $( \pm S D)$ & $47.02(7.31)$ & $48.51(7.05)$ & $0.3 \mathrm{I}^{\mathrm{b}}$ \\
\hline $\begin{array}{l}\text { Years of working: mean } \\
( \pm S D)\end{array}$ & $17.07(9.62)$ & 15.78 (II.08) & $0.54^{b}$ \\
\hline
\end{tabular}

Notes: a Chi square and 'Student's $t$-test. Abbreviation: PA, physical activity. 
Table 2 Comparison of WC, BMI, systolic BP, diastolic BP, physical activity, Food Frequency Questionnaire score, knowledge of MetS, perception of MetS and risk factors, and stress assessment at baseline and 3rd month $(n=100)$

\begin{tabular}{|c|c|c|c|c|c|c|c|}
\hline \multirow[t]{3}{*}{ Variables } & \multirow[t]{3}{*}{ Time } & \multicolumn{2}{|l|}{ Group } & \multirow{3}{*}{$\begin{array}{l}\text { Mean } \\
\text { difference }\end{array}$} & \multirow[t]{3}{*}{$P$-value } & \multirow{2}{*}{\multicolumn{2}{|c|}{$\begin{array}{l}95 \% \text { confidence } \\
\text { interval }^{\mathrm{a}}\end{array}$}} \\
\hline & & \multirow{2}{*}{$\begin{array}{l}\text { Intervention } \\
\text { Mean } \pm \text { SD }\end{array}$} & \multirow{2}{*}{$\frac{\text { Control }}{\text { Mean } \pm \text { SD }}$} & & & & \\
\hline & & & & & & Lower & Upper \\
\hline \multirow[t]{2}{*}{ WC (cm) } & Baseline & $89.07 \pm 8.34$ & $87.75 \pm 7.12$ & -1.32 & 0.40 & -4.40 & 1.77 \\
\hline & 3rd month & $87.44 \pm 7.74$ & $87.86 \pm 7.37$ & 0.42 & 0.78 & -2.58 & 3.41 \\
\hline \multirow[t]{2}{*}{ BMI $\left(\mathrm{kg} / \mathrm{m}^{2}\right)$} & Baseline & $27.28 \pm 4.16$ & $27.16 \pm 3.79$ & -0.12 & 0.88 & -1.70 & 1.46 \\
\hline & 3rd month & $26.98 \pm 3.91$ & $26.83 \pm 3.89$ & -0.15 & 0.85 & -1.70 & 1.40 \\
\hline \multirow[t]{2}{*}{ Systolic BP (mmHg) } & Baseline & $130.55 \pm 22.93$ & $127.67 \pm 17.14$ & -2.88 & 0.48 & -10.87 & 5.10 \\
\hline & $3 r d$ month & $125.48 \pm 17.60$ & $132 \pm 10.46$ & 7.20 & 0.04 & 0.29 & |4.1| \\
\hline \multirow[t]{2}{*}{ Diastolic BP (mmHg) } & Baseline & $78.57 \pm 14.84$ & $80.27 \pm 10.64$ & 1.70 & 0.51 & -3.42 & 6.82 \\
\hline & 3rd month & $74.66 \pm 12.66$ & $82.96 \pm 9.55$ & 8.30 & $<0.001$ & 3.85 & 12.75 \\
\hline \multirow[t]{2}{*}{ Physical activity, MET-minute/week } & Baseline & $|228.74 \pm| 704.79$ & $1 \mid 89.22 \pm 1041.97$ & -39.52 & 0.90 & -689.79 & 610.76 \\
\hline & 3rd month & $1092.72 \pm 791.78$ & $727.00 \pm 746.43$ & -365.72 & 0.05 & -724.96 & -6.49 \\
\hline \multirow[t]{2}{*}{ Food Frequency Questionnaire score } & Baseline & $61.34 \pm 12.59$ & $62.22 \pm 10.45$ & 0.040 & 0.99 & -4.76 & 4.84 \\
\hline & 3rd month & $62.59 \pm 10.77$ & $58.06 \pm 11.57$ & -1.00 & 0.66 & -5.49 & 3.49 \\
\hline \multirow[t]{2}{*}{ Knowledge of MetS } & Baseline & $13.72 \pm 1.37$ & $13.40 \pm 1.39$ & -0.32 & 0.25 & 0.87 & 0.23 \\
\hline & 3rd month & $14.22 \pm 0.89$ & $13.52 \pm 1.09$ & -0.70 & $<0.001$ & -1.10 & -0.31 \\
\hline \multirow[t]{2}{*}{ Perception of MetS and risk factors } & Baseline & $57.16 \pm 11.88$ & $55.02 \pm 10.91$ & -2.14 & 0.35 & -6.66 & 2.37 \\
\hline & 3rd month & $58.52 \pm 9.80$ & $50 \pm 12.54$ & -8.52 & $<0.001$ & -12.99 & -4.05 \\
\hline \multirow[t]{2}{*}{ Stress assessment score } & Baseline & $33.82 \pm 9.94$ & $36.28 \pm 10.38$ & 2.46 & 0.23 & -1.57 & 6.49 \\
\hline & 3 rd month & $31.98 \pm 9.06$ & $37.48 \pm 8.4 \mid$ & 5.50 & 0.002 & 2.03 & 8.97 \\
\hline
\end{tabular}

Notes: Based on estimated marginal means. MET (minutes/week activity) = metabolic equivalent task minute per week. ${ }^{\mathrm{a} A d j u s t m e n t}$ for multiple comparisons: Bonferroni. Abbreviations: BMI, body mass index; BP, blood pressure; MetS, metabolic syndrome; WC, waist circumference.

There were statistically significant differences in the mean of diastolic BP and diastolic $\mathrm{BP}(P=0.04$ and $P<0.001$, respectively) between the intervention group and the control group. PA, knowledge of MetS, perception of MetS and risk factors, and stress assessment score readings between the baseline and the 3-month follow-up also showed statistical differences $(P=0.05, P<0.001, P<0.001$, and $P=0.002$, respectively). There were no statistically significant differences in mean difference (post-pre) of WC, BMI, and FFQ score; however, those findings showed positive improvement changes. The results showed the mean differences (post-pre) of WC and BMI decreased at 3 months, so the current study had a positive influence in the overall PA of participants. Also, there was a higher FFQ score in the intervention group at 3 months indicating a correlation to lower dietary energy intake and increased awareness of the benefits of a healthier diet (Table 2).

From baseline to 3 months, the intervention group showed significant improvements in mean $\mathrm{WC}(1.63 \mathrm{~cm}, P<0.001)$, systolic BP $(5.07 \mathrm{mmHg}, P=0.03)$, diastolic BP $(3.91 \mathrm{mmHg}$, $P=0.02)$, and knowledge of MetS ( 0.50 points, $P=0.02)$ (Table 3), while the control group showed no significant differences. The findings of the control group showed that PA was reduced and FFQ score was reduced indicating a correlation to higher dietary energy intake and a tendency to unhealthy dietary intake (Tables 3 and 4).

\section{Discussion}

It is difficult for individuals to make significant lifestyle changes within a short period of time ( 3 months) and without support and encouragement from their peers. In order to ensure a greater chance of success, support groups are considered to be critically helpful. Group activity, including the opportunity to share personal experiences and exchange ideas for improving personal health, has proven benefits. ${ }^{33}$ In this study, during the 3-month intervention, educational sessions or group discussion by peer leaders encouraged participants to share experiences with one another and learn more about the benefits of healthy eating and regular PA. As a result of this study, participants were informed about calorie counting and knew to select appropriate dishes for each meal to suit the energy needs for their work. Furthermore, they are now more interested in exercise and have organized group exercise sessions lasting 30 minutes in the factory before going home. These activities were initiated and supported by peer leaders.

This program had a significant effect on controlling both systolic BP and diastolic BP in the experimental group, the results of which are consistent with the results from prior studies of peer-led groups. First, the present study is consistent with the effects of the peer support groups that have shown improvements in BP control. ${ }^{34}$ Second, the results are similar to peer-led diabetes education programs in high-risk Mexican 
Table 3 Pairwise comparisons of the different measurements of WC, BMI, systolic BP, diastolic BP, physical activity, Food Frequency Questionnaire score, knowledge of MetS, perception of MetS and risk factors, and stress assessment of the intervention group ( $\mathrm{n}=50$ )

\begin{tabular}{|c|c|c|c|c|c|c|}
\hline \multirow[t]{2}{*}{ Variables } & \multirow[t]{2}{*}{ Time } & & \multirow{2}{*}{$\begin{array}{l}\text { Mean } \\
\text { difference }\end{array}$} & \multirow[t]{2}{*}{$P$-value } & \multicolumn{2}{|c|}{$95 \%$ confidence interval ${ }^{a}$} \\
\hline & & & & & Lower & Upper \\
\hline WC $(\mathrm{cm})$ & Baseline & 3rd month & $1.63^{*}$ & $<0.001 *$ & 0.68 & 2.58 \\
\hline BMI $\left(\mathrm{kg} / \mathrm{m}^{2}\right)$ & Baseline & 3rd month & 0.30 & 0.90 & -0.05 & 0.65 \\
\hline Systolic BP (mmHg) & Baseline & 3rd month & $5.07 *$ & $0.03 *$ & 0.45 & 9.69 \\
\hline Diastolic BP (mmHg) & Baseline & 3rd month & $3.91 *$ & $0.02 *$ & 0.68 & 7.14 \\
\hline Physical activity, MET-minute/week & Baseline & 3rd month & 136.01 & 0.54 & -307.26 & 579.28 \\
\hline Food Frequency Questionnaire score & Baseline & 3rd month & 3.12 & 0.09 & -0.54 & 6.78 \\
\hline Knowledge of MetS & Baseline & 3rd month & $-0.50 *$ & $0.02 *$ & -0.92 & -0.09 \\
\hline Perception of MetS and risk factors & Baseline & 3rd month & -1.36 & 0.51 & -5.44 & 2.72 \\
\hline Stress assessment score & Baseline & 3rd month & 1.84 & 0.24 & -0.23 & 4.91 \\
\hline
\end{tabular}

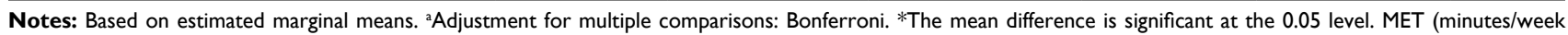
activity) $=$ metabolic equivalent task minutes per week.

Abbreviations: BMI, body mass index; BP, blood pressure; MetS, metabolic syndrome; WC, Waist circumference.

Table 4 Pairwise comparisons of the different measurements of WC, BMI, systolic BP, diastolic BP, physical activity, Food Frequency Questionnaire score, knowledge of MetS, perception of MetS and risk factors, and stress assessment of the control group ( $\mathrm{n}=50$ )

\begin{tabular}{|c|c|c|c|c|c|c|}
\hline \multirow[t]{2}{*}{ Variables } & \multirow[t]{2}{*}{ Time } & & \multirow{2}{*}{$\begin{array}{l}\text { Mean } \\
\text { difference }\end{array}$} & \multirow[t]{2}{*}{$P$-value } & \multicolumn{2}{|c|}{$95 \%$ confidence interval $^{a}$} \\
\hline & & & & & Lower & Upper \\
\hline WC (cm) & Baseline & 3rd month & -0.11 & 0.82 & -1.06 & 0.84 \\
\hline BMI $\left(\mathrm{kg} / \mathrm{m}^{2}\right)$ & Baseline & $3 r d$ month & 0.33 & 0.07 & -0.02 & 0.68 \\
\hline Systolic BP (mmHg) & Baseline & 3rd month & -2.88 & 0.48 & -10.87 & 5.10 \\
\hline Diastolic BP $(\mathrm{mmHg})$ & Baseline & 3rd month & -2.70 & 0.10 & -5.92 & 0.54 \\
\hline Physical activity, MET-minute/week & Baseline & 3rd month & $462.22^{*}$ & 0.03 & 48.34 & 876.10 \\
\hline Food Frequency Questionnaire score & Baseline & 3rd month & 4.16 & 0.03 & 0.50 & 7.82 \\
\hline Knowledge of MetS & Baseline & 3rd month & -0.12 & 0.57 & -0.53 & 0.29 \\
\hline Perception of MetS and risk factors & Baseline & 3rd month & -2.14 & 0.35 & -6.66 & 2.38 \\
\hline Stress assessment score & Baseline & 3rd month & -1.20 & 0.44 & -4.27 & 1.87 \\
\hline
\end{tabular}

Notes: Based on estimated marginal means. ${ }^{a}$ Adjustment for multiple comparisons: Bonferroni. *The mean difference is significant at the 0.05 level. MET (minutes/week activity) $=$ metabolic equivalent task minutes per week.

Abbreviations: BMI, body mass index; BP, blood pressure; MetS, metabolic syndrome; WC, Waist circumference.

Americans,${ }^{20}$ which showed significant time-by-group interaction effects for BP.

The MET-minute/week score was found to be significantly different after implementation by peer leaders between groups. This finding is similar to Chang et al's $\mathrm{s}^{35}$ study on applied nurse-led empowerment strategies for hypertension patients with MetS where it was found that the amount of mid- and high-intensity activities did not increase, but the increased amount of walking resulted in a positive change in overall PA. This sets an important precedent in helping participants make better lifestyle choices, which have significant long-term benefits.

The current study found that the consumption of FFQ score was not significantly different. This contrasted with the study of a promotora-led lifestyle behavior intervention for overweight women aged 35-64 years. The findings showed that women in the intervention group improved significantly in dietary habits. ${ }^{36} \mathrm{~A}$ possible reason for the lack of improvement in the FFQ score is the easy access to soft drinks and fast food that are high in sugar, oil, and salt sold in the factory cafeterias, making it difficult for staff to break away from the convenience of these food options. However, there were marginal positive changes in the mean FFQ score of participants indicating improved eating behaviors. It is hoped that a change in eating habits would result in changes in fast food items sold in the cafes. Change in dietary habits depends, to a large extent, on the environment where the people live and work.

Furthermore, people with better access to social support feel more empowered to make changes in behavior, which ultimately leads to achieving target goals in health and fitness. ${ }^{37} \mathrm{~A}$ better understanding of MetS as experienced by participants is similar to a previous study reporting that participants' knowledge and attitudes toward MetS risks such as nutrition, PA, and engagement in PA were statistically improved. ${ }^{38}$

It was found that stress was at the same level (severe level), but after the 3 months intervention, the mean score had decreased significantly. The study revealed that there were relationships between the psychosocial work environment and psychological health problems among Thai garment workers where high scores on psychosomatic symptoms, 
anxiety, and depression were reported $(24.9,23.7$, and 18.2\%, respectively). ${ }^{39}$ In the present study, there are some factors that might influence increased stress such as workload and time management: each day's workload changes but includes strict deadlines that all participants feel obliged to meet resulting in little time for relaxation. This led to irregular or minimal break times with each employee having to manage her own breaks to ensure that all work was completed on time.

In interpreting these findings, it is important to consider the following limitations: first, the duration of this study was limited to 12 weeks, which only allowed for an assessment of the short-term impact of the changing MetS risk factors or health risk behaviors. Ideally, this approach should be evaluated over a longer period in order to understand more of the sustainability of a peer-led intervention program and also in order to ensure long-term reduction of MetS risk factors. Second, this study was applied specifically to female workers in a Uniform Sewing Military Factory, so findings and methods cannot simply be applied to the general population but may be useful for other sedentary occupations within a regulated working regime. In future research, the use of a more standardized process of selecting participants for both the control and intervention groups is recommended: both categories of participants should ideally be in the same controlled study workplace to ensure that environment and workplace factors are more accurately assessed, but this would require stricter and more regular supervision from the research team in order to ensure that information was not shared between groups. In addition, employing a randomized controlled design with full cost-effectiveness analyses would provide a more thorough examination of the program. Finally, the data collection method was based on a self-administered questionnaire, which may have resulted in biased responses that could not be verified. As a recommendation for future assessments, researchers should explore the interaction and developmental process among peer groups as it may be helpful in the understanding, standardization, and dissemination of peer-led intervention. Last but not least, reducing MetS in the workplace could be ensured if organizational support (such as workstation and workplace modifications) were introduced in order to reduce occupational sitting time.

\section{Conclusion}

Introducing a peer-led intervention program for individuals with a risk of MetS resulted in positive results. The research results showed a significantly improved reduction in major health risk factors, and furthermore, due to the efforts of the peer leaders, the study had a high retention rate and received reassuringly positive feedback from participants.

\section{Acknowledgments}

This study was supported by the 90th Anniversary of Chulalongkorn University Scholarship under the Ratchadaphisek Somphot Fund, Chulalongkorn University (Grant no GCUGR1125594023D). The authors thank Mrs Marina Moore, College of Public Health Sciences, Chulalongkorn University.

\section{Disclosure}

The authors report no conflicts of interest in this work.

\section{References}

1. Institute for Clinical Systems Improvement (ICSI) [webpage on the Internet]. Obesity for Adults, Prevention and Management of. 2015. Available from: https://www.icsi.org/guidelines_more/catalog_guidelines_and_more/catalog_guidelines/catalog_endocrine_guidelines/ obesity_adults/. Accessed October 15, 2016.

2. Aekplakorn W. Prevalence, treatment, and control of metabolic risk factors by BMI status in Thai adults: National Health Examination Survey III. Asia Pac J Public Health. 2011;23(3):298-306.

3. Aekplakorn W. Prevalence and trends of obesity and association with socioeconomic status in Thai adults: national health examination surveys, 1991-2009. J Obes. 2014;2014:8.

4. Teerawattananon Y, Luz A. Asian Development Bank Institute. Obesity in Thailand and its economic cost estimation. Available from: https:// www.adb.org/publications/obesity-thailand-and-its-economic-costestimation. Accessed June 26, 2017.

5. Blackford K, Jancey J, Lee A, et al. A randomised controlled trial of a physical activity and nutrition program targeting middle-aged adults at risk of metabolic syndrome in a disadvantaged rural community. $B M C$ Public Health. 2015;15:284.

6. Cheong W. S [webpage on the Internet]. Overweight and Obesity in Asia. Underwriting Focus, no. 2014. Available from: http://www.genre. com/knowledge/publications/uwfocus14-2-cheong-en.html. Accessed September 25, 2016.

7. Institute for clinical systems improvement (ICSI). Obesity for adults, prevention and management of. 2015. Available from: https://www. icsi.org/guidelines_more/ catalog_guidelines_and_more/catalog guidelines/catalog_endocrine_guidelines/ obesity_adults/. Accessed September 25, 2016.

8. Pérez-Escamilla R, Hromi-Fiedler A, Vega-López S, Bermúdez-Millán A, Segura-Pérez S. Impact of peer nutrition education on dietary behaviors and health outcomes among latinos: a systematic literature review. J Nutr Educ Behav. 2008;40(4):208-225.

9. Lujan J. The Effectiveness of a Promotora-Led Intervention for Mexican Americans with Type 2 Diabetes. (Doctor of Science in Nursing), The University of Texas Health Science Center at Houston, ProQuest Information and Learning Company; 2007.

10. MacPherson SL, Joseph D, Sullivan E. The benefits of peer support with diabetes. Nurs Forum. 2004;39(4):5-12.

11. Keyserling TC, Samuel-Hodge CD, Ammerman AS, et al. A randomized trial of an intervention to improve self-care behaviors of African American women with type 2 diabetes. Diabetes Educ. 2002;26:796-805.

12. Shen H. Effectiveness of a Peer-Led Self-Management Program for Older People with Type 2 Diabetes in China. (Doctor of Philosophy), Queensland University of Technology; 2008.

13. Funnell MM. Peer-based behavioural strategies to improve chronic disease self-management and clinical outcomes: evidence, logistics, evaluation considerations and needs for future research. Fam Pract. 2010;27(supp11):i17-i22.

14. Thaiprayoon S, Smith R. Capacity building for global health diplomacy: Thailand's experience of trade and health. Health Policy Plan. 2015;30(9):1118-1128. 
15. Chavasit V, Kasemsup V, Tontisirin K. Thailand conquered undernutrition very successfully but has not slowed obesity. Obes Rev. 2013;14(suppl 2):96-105.

16. Thotsathit N, Puntumetakul R, Eungpinichpong W, et al. Prevalence of musculoskeletal disorders in sewing occupation in Khon Kaen province. $K K U \operatorname{Res} J(G S)$. 2011;11(2):47-54.

17. Wongbut A, Hansakul A. Health perception factors effect on occupational hazards preventive behaviors among sewing workers in informal sector: a study in Bannonpho, Loomlumchee sub-district, Bankhwao district, Chaiyaphum province. Office Dis Prev Control 6 Khon Kaen. 1969;18(3):34-48.

18. Lumnok N. A muscle pain prevention program based on PRECEDEPROCEED framework and participatory learning: a case study with sewing machine operator at a royal Thai army uniform factory. Nurs $J$ Ministry Public Health. 2010;23(1):34-35.

19. Pirom T, Worachetwarawat P. A Study of Tiredness from Sitting in Working of Sewing Workers in Garment Industry Srivijaya. 2012. Available from: www.dms.eng.su.ac.th/filebox/FileData/WPS030.pdf. Accessed September 5, 2016.

20. Philis-Tsimikas A, Fortmann A, Lleva-Ocana L, Walker C, Gallo LC. Peerled diabetes education programs in high-risk Mexican Americans improve glycemic control compared with standard approaches: a project Dulce promotora randomized trial. Diabetes Care. 2011;34(9):1926-1931.

21. Doustmohammadian A, Keshavarz SA, Doustmohammadian N, et al. Patterns of physical activity and dietary habit in relation to weight status in adolescent girls. J Paramed Sci. 2013;4(2):2-10.

22. World Health Organization. Physical Status: The Use and Interpretation of Anthropometry. 1995. Available from: http:/apps.who.int/iris/ bitstream/10665/37003/1/WHO_TRS_854.pdf. Accessed May 25, 2017.

23. Wang J, Thornton JC, Bari S, et al. Comparisons of waist circumferences measured at 4 sites. Am J Clin Nutr. 2003;77(2):379-384.

24. Centers for Disease Control and Prevention. National Health and Nutrition Examination Survey (NHANES) Health Tech/Blood Pressure Procedures Manual [Press Release]. 2009. Available from: https://www.cdc. gov/nchs/data/nhanes/nhanes_09_10/bp.pdf. Accessed March 20, 2017.

25. Johnson RK. Dietary intake - how do we measure what people are really eating? Obes Res. 2002;10(1):63s-67s.

26. Block G, Clifford C, Naughton MD, Henderson M, McAdams M. A brief dietary screen for high fat intake. JNutr Edu. 1989;21(5):199-207.

27. Sasinil S. The Effectiveness of Nutrition Counseling, Health Belief, Self-Care Behavior Program among Overweight Women [dissertation]. Mahidol University; 1998
28. Abdullakasim P. Effectiveness of Healthy Organization by Participatory Encouragement (HOPE) Project on Reducing Cardiovascular Risk Factors in Employees of the Electric Generating Authority of Thailand (EGAT) [dissertation]. Chulalongkorn University; 2012.

29. Aekplakorn W, Satheannoppakao W, Putwatana P, et al. Dietary pattern and metabolic syndrome in Thai adults. $J$ Nutr Metab. 2015; 2015:10.

30. Ainsworth BE, Haskell WL, Whitt MC, et al. Compendium of physical activities: an update of activity codes and MET intensities. Med Sci Sports Exerc. 2000;32(9 Suppl):S498-504.

31. Juckaphan S, Chuphayun L, Chaiyasit W, et al. Development of Thai Computerized Self-Analysis Stress Test. Bangkok, Thailand: Department of Mental Health; 1995.

32. Nicolas W. Self-Scoring Personal Analysis Test: How Well Do You Cope With Stress? Understanding Human Behavior. New York: BPC Publishing Limited; 1974

33. Association of Brethren Caregivers [webpage on the Internet]. Wellness Ministry to Prevent and Treat Metabolic Syndrome. 2016. Available from: www.CaregivingMinistries.org. Accessed September 7, 2016.

34. Tang TS, Funnell MM, Sinco B, Spencer MS, Heisler M. Peer-led, empowerment-based approach to self-management efforts in diabetes (PLEASED): a randomized controlled trial in an African American community. Ann Fam Med. 2015;13(1):S27-S35.

35. Chang KA, Fritschi C, Kin JM. Nurse-led empowerment strategies for hypertension patients with metabolic syndrome. Contemp Nurse. 2012;42(1):118-128.

36. Koniak-Griffin D, Brecht ML, Takayanagi S, Villegas J, Melendrez M, Balcázar H. A community health worker-led lifestyle behavior intervention for Latina (Hispanic) women: feasibility and outcomes of a randomized controlled trial. Int J Nurs Stud. 2015;52(1):75-87.

37. Courney KS, McAuley E. Cognitive mediations of the social influence exercise adherence relationship: a test of the theory of planned behavior. J Behav Med. 1995;18(15):499-515.

38. Robinson V [webpage on the Internet]. The Effect of a Peer-Led Nutrition and Physical Education Intervention on Behavior (Order No. 3565601). [ProQuest Dissertations \& Theses Global (1415421152)]; 2013. Available from: https://search.proquest.com/docview/1415421152? Accounted $=15637$. Accessed October 10, 2016

39. Buapetch A, Kalampakorn S, Lagampan S. Psychosocial work environment factors relating to psychological health problems and job satisfaction of Thai workers in large-sized garment factories. J Public Health. 2012;42(1):5-17.
Journal of Multidisciplinary Healthcare

\section{Publish your work in this journal}

The Journal of Multidisciplinary Healthcare is an international, peerreviewed open-access journal that aims to represent and publish research in healthcare areas delivered by practitioners of different disciplines. This includes studies and reviews conducted by multidisciplinary teams as well as research which evaluates the results or conduct of such teams or health

\section{Dovepress}

care processes in general. The journal covers a very wide range of areas and welcomes submissions from practitioners at all levels, from all over the world The manuscript management system is completely online and includes a very quick and fair peer-review system. Visit http://www.dovepress.com/ testimonials.php to read real quotes from published authors. 